\title{
How alternative food networks work in a metropolitan area? An analysis of Solidarity Purchase Groups in Northern Italy
}

\author{
Lucia Baldi $^{1}$, Danilo Bertoni ${ }^{1 *}$ (D, Giuseppina Migliore ${ }^{2}$ and Massimo Peri ${ }^{1}$
}

\footnotetext{
* Correspondence: danilo.bertoni@ unimi.it

${ }^{1}$ Department of Environmental Science and Policy, Università degli Studi di Milano, Via Celoria 2, Milan, Italy

Full list of author information is available at the end of the article
}

\begin{abstract}
Our paper focuses on Solidarity Purchase Group (SPG) participants located in a highly urbanized area, with the aim to investigate the main motivations underlining their participation in a SPG and provide a characterization of them. To this end, we carried out a survey of 795 participants involved in 125 SPGs in the metropolitan area of Milan (Italy). Taking advantage of a questionnaire with 39 questions, we run a factor analysis and a two-step cluster analysis to identify different profiles of SPG participants. Our results show that the system of values animating metropolitan SPG practitioners does not fully conform to that traditionally attributed to an alternative food network (AFN). In fact, considerations linked to food safety and healthiness prevail on altruistic motives such as environmental sustainability and solidarity toward small producers. Furthermore, metropolitan SPGs do not consider particularly desirable periurban and local food products. Observing the SPGs from this perspective, it emerges as such initiatives can flourish also in those places where the lack of connection with the surrounding territory is counterbalanced by the high motivation to buy products from trusted suppliers who are able to guarantee genuine and safe products, not necessarily located nearby.
\end{abstract}

Keywords: Short supply chain, Local food, Consumers' behavior, Highly urbanized area, Two-step cluster analysis

JEL classification: P25, P46, 115, Q13, Q56

\section{Introduction}

The industrialization and globalization of food markets respond to a system of economic organization that has led to a general reduction in product prices and to the consolidation of long production chains in which food loses its identity and its cultural value (Contini et al. 2017; Del Giudice et al. 2015; Migliore et al. 2014a; Xu and Wang 2014). This has contributed to the creation of new strategies in consumption policies, which has seen the birth and development of different forms of alternative food networks (AFNs), particularly in the USA and Europe (Micheels and Boecker 2017; Giampietri et al. 2016; Galli et al. 2015). AFNs aim to provide sustainable alternatives to the industrialized and globalized food markets (Carbone 2017; Hemmerling et al. 2015) and have been conceptualized as the consumers' resistance to a placeless, unsustainable, and unjust industrialized food system (Tregear 2011). A new form of

(c) The Author(s). 2019 Open Access This article is distributed under the terms of the Creative Commons Attribution 4.0 International License (http://creativecommons.org/licenses/by/4.0/), which permits unrestricted use, distribution, and reproduction in any medium, provided you give appropriate credit to the original author(s) and the source, provide a link to the Creative Commons license, and indicate if changes were made. 
consumer behavior is thus emerging, where consumers use the market as an arena for a critical dialog with the globalized food system (Graziano and Forno 2012; Cembalo et al. 2013). Consumers seem to rediscover their political power, transforming themselves into critical citizens (Norris 1999). Many different forms of AFNs exist, including farmers market, farm shops, box schemes, and community-supported agriculture (CSA) (Hashem et al. 2018; Migliore et al. 2015). Among these forms, particularly interesting is the proliferation of Solidarity Purchasing Groups (SPGs) in Italy (Migliore et al. 2014b; Cembalo et al. 2013; Graziano and Forno 2012). Lombardi et al. (2015) showed that SPG members exhibited strong altruistic values compared to other consumers, in which the interest in preserving, protecting, and sustaining the welfare of other people are important factors of SPG participation. Moreover, SPGs have been conceptualized as consumers' groups characterized by a strong sense of community whose demand is strongly influenced by environmental, ethical, and food safety concerns (Sacchi 2018; Cembalo et al. 2013; Graziano and Forno 2012). An interesting trait of SPGs is that they allow building personal interaction between producers and consumers, which appears to be highly valued by consumers as means to build relationships of trust, ensuring the authenticity of the production (Hashem et al. 2018; Migliore et al. 2014a). SPG members seem to exhibit a strong connection with the food that is produced near the place where they live (Lombardi et al. 2015). In this context, local food is perceived to be better for the environment and also for society. This arises from consumers' concerns to reduce the environmental costs of food production and distribution including transportation of food across the globe (Cembalo et al. 2013; Sage 2014). According to Winter (2003), the turn to local in the food market has developed around consumers' anxiety over health scares, coupled with environmental and ethical concerns. The latter is associated with the marginalization of small farms from globalized markets (Zepeda and Leviten-Reid 2004). Buying local food consumers contribute to supporting local rural communities, by recirculating financial capital, creating new jobs, and encouraging new forms of sustainable entrepreneurship (Lombardi et al. 2015). The emphasis laid by the consumers upon the locality of production, as pointed out by Gilg and Battershill (1998), includes the rediscovery of values of social connection, such as nostalgia which harks back to a perceived time of real and wholesome foods, along with the great consumer recognition of product authenticity (Kuznesof et al. 1997). Local food has been described in the literature as a key factor in the development of AFNs worldwide (Lombardi et al. 2015; Winter 2003). According to Feenstra (1997), AFNs "are rooted in particular places, aim to be economically viable for farmers and consumers, use ecologically sound production and distribution practices and enhance social equity and democracy for all members of the community" (Feenstra 1997, p. 28). The establishment of these forms seems influenced by the territorial context where they take place, which includes the characteristics of local agriculture, as well as the geographical constrains of periurban areas (Blasi et al. 2015). Blasi et al. (2015) highlighted that among the characteristics recognized in AFNs, the relational proximity between producers and consumers and a short geographical distance between them are among the most important factors characterizing AFNs.

This has been confirmed in the current literature on Italian SPGs, where local food and the direct relationship of trust between producers and consumers represent key factors of consumers' participation. For example, Graziano and Forno (2012) underlined how direct relationships with producers are core elements of SPG characterization, in 
which mutual trust and solidarity connecting SPG members with local producers are supported "by regular meetings to further support the producer-consumer relationship" (Graziano and Forno, 2012: 124). The choice of which farmers to form relations with is motivated by the sharing of values and identity, on the proximity of the area of production, and on the basis of the principle of solidarity. Indeed, SPGs support small/mid-scale farming, which is marginal with respect to the global market (Graziano and Forno 2012).

However, these studies have been carried out in places characterized by well-established periurban agriculture and by the availability of small farms, which adopt ethical principles of production, a few kilometers from the cities (Lombardi et al. 2015; Migliore et al. 2014a; Cembalo et al. 2013; Brunori et al. 2012; Graziano and Forno 2012).

In this regard, it is worth noting that many SPGs in Northern Italy are located in metropolitan areas characterized by a high urbanization level, where local small farms providing food to SPGs are almost absent. According to the national network of SPGs' ${ }^{1}$ data, about $27 \%$ of Italian SPGs are located in the Lombardy region, and about one half of them carry out their activity in the metropolitan area of Milan. The latter is characterized by a high urbanization level or by a presence of large farms oriented to commodity productions (mainly livestock products and cereals-ISTAT, 2011).

To the best of our knowledge, no study has explored the main motivations underlining SPG participation in metropolitan areas. What emerges is a gap in research regarding the motivations of consumers to participate in the Italian SPGs in these particular metropolitan areas, where SPGs seem to be more spread than in other contexts.

Therefore, the aim of this study is to provide a characterization of SPG participants who live in metropolitan areas and to understand the main motivations underlining their participation.

This study tries to contribute to enhancing understanding about AFNS in Italy, by exploring which consumers' motivations characterize their functioning in the Italian metropolitan areas. The next section is dedicated to present the methodological approach used to analyze SPG participants in metropolitan areas. The following are the main results and discussions presented.

\section{Materials and methods}

\section{The reference area}

Our study took place in some provinces of the Lombardy region in Northern Italy, which constitute the metropolitan area of the city of Milan. Such territory is characterized by a very high degree of urbanization and population density as highlighted in Fig. 1.

Notably, Lombardy, and particularly the metropolitan area of Milan, concentrates a relevant portion of Italian economic activities. In fact, the region produces about $22 \%$ of Italian Gross Domestic Product, and $25 \%$ of the industry value was added while having only $16.5 \%$ of inhabitants. As a consequence, the GDP per capita of Lombardy is 35\% higher than the Italian one (data 2016 extracted from Italian National Institute of Statistics data warehouse). On the one hand, this large concentration of population and

${ }^{1}$ It is a national network of SPGs, available on website www.retegas.org, in which SPGs enroll on a voluntary basis and in which are described the main events (national meetings, solidarity economy fairs, etc.) of interest for SPGs participants. 


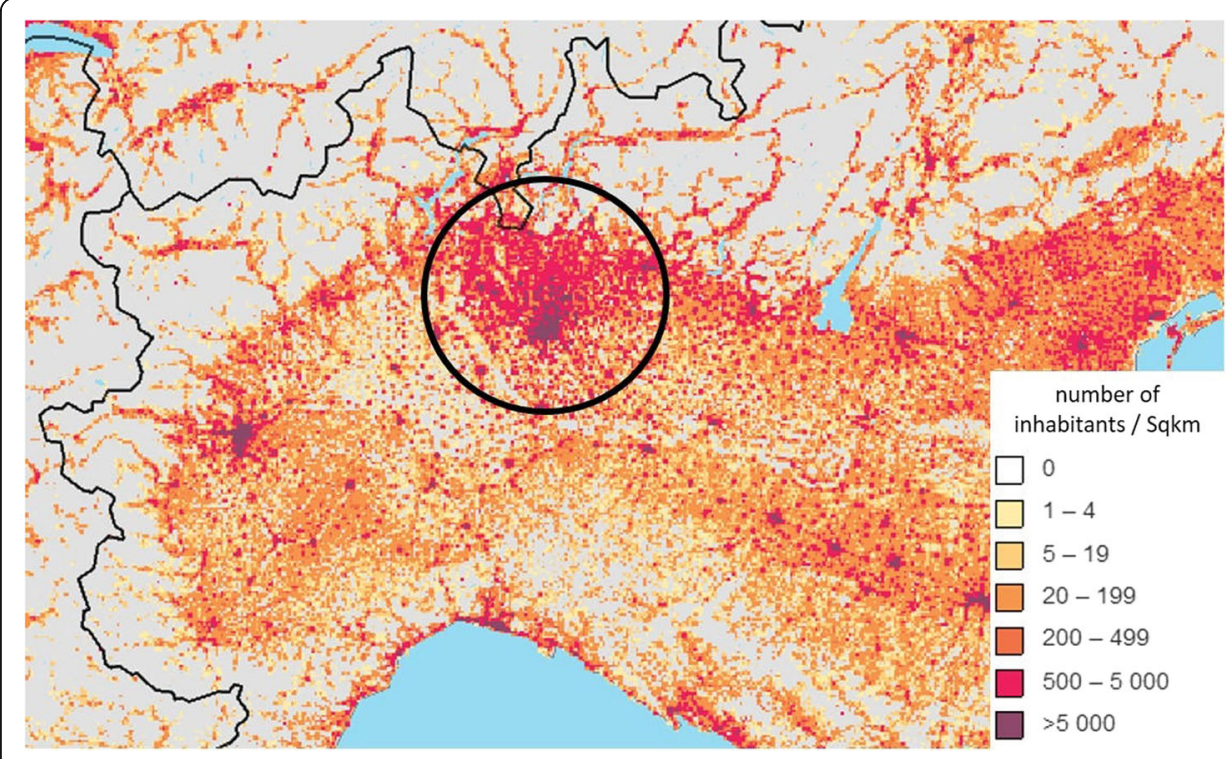

Fig. 1 Population density in the reference area. Source: JRC, Eurostat, GEOSTAT Population Grid 2011

productive activities in a small area has determined positive effects on the economic welfare, and on the other hand, it negatively affected the environment (Canedoli et al. 2018; EEA 2015; De Meij et al. 2009) and population health (Angelici et al. 2016; Esposito et al. 2014). In the reference area, the urbanized contexts are framed with territories characterized by a high-intensity farming activity, mainly based on dairy, pig, and cereal farms (Caiani et al. 2018). Particularly, the Lombardy farms, while representing only $3.6 \%$ of Italian farms, manage $7.6 \%$ of the total Italian utilized agricultural area and contribute for the $13.6 \%$ of the national agricultural value of production. As a consequence, Lombardy farms are on average large in size both physically (2.1 greater than the Italian average and 1.4 in respect to EU-28) and economically (4.7 times higher than the national average and 6.0 times in comparison to EU-28). In the region, the value added per labor unit in the primary sector is comparable in magnitude to that of the other economic sectors, while in Italy, it is much lower (Pieri and Pretolani 2017). Despite such a farming model guarantees farm economic viability; it is often perceived as not sustainable from the environmental viewpoint (Lombardi et al. 2017; Tempesta and Vecchiato 2013; Travisi and Nijkamp 2008).

The main part of farms in the belt of Milan is aimed at a wholesale market, though an increasing, but still limited, rate of them is turning into a multifunctionality key, mainly developing short supply chains and direct marketing solutions (for instance, by opening a farm shop or participating in farmers' markets) (Paracchini et al. 2015). However, these subjects facet an increasing social demand for rural lifestyle and multiple goods offered by agriculture (amenities, leisure and recreation, regional food supply); at the same time, they suffer from their location in an area characterized by strong environmental pressure from urban settlements. Notably, $14.5 \%$ of Lombardy land is urbanized (including residential and industrial areas, as well as infrastructures), but this value rises to about $50 \%$ in the most urbanized contexts (Caiani et al. 2015). 


\section{The questionnaire}

To provide a profile of SPG members and investigate the motivations underlining their participation in this kind of network, we conducted a survey in the metropolitan area of Milan in Northern Italy. We collected 795 questionnaires from consumers involved in 125 SPGs. According to the national network of SPG (Retegas), these represent about $15 \%$ of the total of SPG in Italy, $25 \%$ of Northern Italy, and about $55 \%$ of Lombardy. To reach our aim, we selected those groups located in Milan and in areas near Milan focusing on patterns of territory continuity. We contacted the SPG network managers that control all the 2000 SPG members located in these areas. By the sampling lists provided by these managers, we sent the questionnaire to all these members and obtained a response rate of $39.7 \%$. Thus, our sample appears highly representative of the area selected.

The study was provided during the period from January to March 2017 to online respondents by sharing a link generated through the use of Google Forms. The link was sent exclusively to SPG participants' addresses using this sampling list. The advantages of a web survey include access to individuals in distant or difficult to reach locations and the convenience of having automated unbiased, low cost, and high-speed data collection (Wright 2006). In contrast, older individuals may be more difficult to reach since they are less likely to be online (Lenhart et al. 2003). However, some studies carried out in Italy (Graziano and Forno 2012; Cembalo et al. 2012; Fonte 2013; Grasseni 2013; Migliore et al. 2014a) reported the SPG phenomenon is typically associated with middle-aged consumers, so we conclude this way should be useful to reach our aim.

To construct the survey, we follow the empirical framework of Brunsø and Grunert's (1995) and Martino et al. (2016) that consider some food-related lifestyle set of variables. The questionnaire was divided into the following seven sections: (a) socio-demographic characteristics, (b) characterization of SPG consumers, (c) solidarity with producers/territory, (d) economic convenience and services, (e) environmental issues, (f) socialization, and (g) quality, food safety, and health. The first group of questions contains variables like age, education, and income. The second group asks participants the SPG attendance time, the role inside SPG, and the percentage of expenditure from SPGs. The third set investigates the importance of local food and the link with producers. The fourth group encloses questions like the importance of price, e-commerce, and traceability. The fifth group deals with the importance of water and energy consumption during the production process, carbon emissions, and use of pesticides. The sixth group tries to discover if respondents consider purchase as an act of socialization and take pleasure in it. The last group focuses on the interest of food characteristics linked to health and quality, like the freshness, being organic, preservative-free, and so on. The questionnaire contains 39 questions, of which 34 use a Likert scale and the remaining 4 or 5 points scale. The description, scale, mean, and entropy measure of the resulting variables are reported in Table 1.

\section{The empirical approach}

In this section, we first analyze the results of the survey describing briefly the sample and the answers of the SPG members; then, we employ a factor analysis to reduce the dimension of data and find factors expressing the most significant features survey. Finally, we use these factors to run a two-step cluster analysis with the aim to identify different groups of SPG members. 
Table 1 Variable description and main descriptive statistics

\begin{tabular}{|c|c|c|c|}
\hline Variable name & Scale & Mean & Entropy index* \\
\hline \multicolumn{4}{|l|}{ Socio-demographic characteristics } \\
\hline Age & - & 49.5 & $10.81^{* *}$ \\
\hline Gender $^{1}$ & \multicolumn{3}{|c|}{2 categories (nominal variable) } \\
\hline Residence & \multicolumn{3}{|c|}{156 categories (nominal variable) } \\
\hline Family size & $1-5$ & 3.1 & 0.64 \\
\hline Education & $1-5$ & 3.6 & 0.49 \\
\hline Employment $^{1}$ & \multicolumn{3}{|c|}{2 categories (nominal variable) } \\
\hline Income & $1-4$ & 2.7 & 0.54 \\
\hline \multicolumn{4}{|l|}{ Characterization of SPG consumers } \\
\hline SPG attendance time & $1-5$ & 3.8 & 0.61 \\
\hline Role inside SPG & $1-4$ & 2.0 & 0.55 \\
\hline$\%$ food expenditure from SPG & $1-4$ & 2.9 & 0.57 \\
\hline Motivation to participate ${ }^{1}$ & \multicolumn{3}{|c|}{5 categories (nominal variable) } \\
\hline \multicolumn{4}{|l|}{ Solidarity with producers/territory } \\
\hline Interest in the ethical content of food & $1-6$ & 4.8 & 0.60 \\
\hline Importance of regional origin & $1-6$ & 4.1 & 0.73 \\
\hline Importance of municipal origin & $1-6$ & 3.6 & 0.78 \\
\hline Importance of supplying from small producers & $1-6$ & 5.2 & 0.51 \\
\hline \multicolumn{4}{|l|}{ Economic convenience and services } \\
\hline Importance of production process information & $1-6$ & 5.0 & 0.59 \\
\hline Importance of nutrition/ingredients information & $1-6$ & 4.9 & 0.61 \\
\hline Influence of the price during the purchase of food products & $1-6$ & 3.8 & 0.62 \\
\hline Frequency in comparing the prices of similar products & $1-6$ & 4.0 & 0.67 \\
\hline Importance of a wide range of similar products during purchase & $1-6$ & 3.6 & 0.67 \\
\hline Importance of purchasing seasonal foods & $1-6$ & 5.5 & 0.37 \\
\hline Importance to save time for food supply & $1-6$ & 4.1 & 0.70 \\
\hline E-commerce utility for buying food & $1-6$ & 3.5 & 0.76 \\
\hline \multicolumn{4}{|l|}{ Environmental issues } \\
\hline Importance of a low-impact packaging during purchases & $1-6$ & 5.1 & 0.53 \\
\hline $\begin{array}{l}\text { Awareness of water consumption with reference to } \\
\text { agro-food production }\end{array}$ & $1-6$ & 4.7 & 0.63 \\
\hline $\begin{array}{l}\text { Awareness about carbon emissions with reference to } \\
\text { agro-food production }\end{array}$ & $1-6$ & 4.7 & 0.63 \\
\hline $\begin{array}{l}\text { Awareness about energy consumption with reference to } \\
\text { agro-food production }\end{array}$ & $1-6$ & 4.7 & 0.63 \\
\hline $\begin{array}{l}\text { Awareness about the use of pesticides with reference to } \\
\text { agro-food production }\end{array}$ & $1-6$ & 5.4 & 0.44 \\
\hline $\begin{array}{l}\text { Awareness about } \mathrm{Km0} 0 \text { products with reference to } \\
\text { agro-food production }\end{array}$ & $1-6$ & 4.7 & 0.64 \\
\hline \multicolumn{4}{|l|}{ Socialization } \\
\hline Pleasure during grocery shopping & $1-6$ & 4.4 & 0.65 \\
\hline Purchase act as a socialization situation & $1-6$ & 4.2 & 0.70 \\
\hline Importance of sharing food choices & $1-6$ & 4.4 & 0.65 \\
\hline
\end{tabular}


Table 1 Variable description and main descriptive statistics (Continued)

\begin{tabular}{llll}
\hline Variable name & Scale & Mean & Entropy index* \\
\hline Quality, food safety, health & & & \\
Importance that a food product is preservative-free & $1-6$ & 5.1 & 0.55 \\
Importance that a food product is organic & $1-6$ & 4.8 & 0.62 \\
Importance that a food product is fresh & $1-6$ & 5.3 & 0.47 \\
Importance that a food product is typical of Italian tradition & $1-6$ & 4.0 & 0.74 \\
Importance that a food product is GMO-free & $1-6$ & 5.3 & 0.49 \\
Importance of knowing and trusting in producers & $1-6$ & 5.3 & 0.47 \\
Propensity to buy new or unknown food products & $1-6$ & 4.5 & 0.63 \\
\hline
\end{tabular}

${ }^{1}$ For these variables, see paragraph "Descriptive results"

*Entropy index refers to the Shannon index and quantifies the uncertainty associated with this prediction. It is calculated as follows: $H^{\prime}=-\sum_{i=1}^{R} p_{i} \log _{e}\left(p_{i}\right)$ where $R$ corresponds to the total number of possible categories in the dataset and $p_{i}$ is the proportion of characters belonging to the ith category. $H$ is equal to zero when all responses belong to a single category, and its maximum value is determined by $H_{\text {max }}^{\prime}=\log _{e}(R)$. When $R$ is equal to 4,5 , and $6, H_{\max }^{\prime}$ is $1.39,1.61$, and 1.79 , respectively. In these cases, there are uniform distributions of responses (Shannon 1948)

**Standard deviation is calculated for "age" variable

Factor analysis is a multivariate statistical tool that simplifies multidimensional variables by dimension reduction. This method models the covariation among a set of observed variables as a function of one or more latent constructs. By extracting a few and independent common factors, the common information and correlation of the original variables are well preserved.

The two-step cluster analysis procedure is an exploratory tool designed to reveal natural groupings within a data set that would otherwise not be apparent. This method was created by SPSS (SPSS 2001) extending the model-based distance measure used by (Banfield and Raftery 1993; Angelici 2016) and utilizing a two-step clustering approach similar to BIRCH (Zhang et al. 1996).

The algorithm employed by this procedure has several desirable features that differentiate it from traditional clustering techniques like the automatic selection of the number of clusters, the ability to create clusters based on both categorical and continuous variables, and the ability to analyze large data files efficiently. This feature is particularly important in our study because we deal with about 800 observations.

\section{Results}

\section{Descriptive results}

In our sample, female respondents decisively prevail on males (65\%). Pointing on the age, only $2.6 \%$ of the respondents belong to the age class " $20-30$ years," whereas $60 \%$ of them are aged between " $40-60$ years". With regard to family size, results indicate that these subjects mainly live in medium-large families with three or four persons (57\%).

The rate of employment is high for both because most of the respondents belong to the working-age class and because they mostly live in a wealthy area, where the employment rate is relatively higher than in the rest of Italy (Istat 2018). SPG participants at the survey benefit from an above-average income (upper-middle income $38.4 \%$ and high income $19.4 \%$ ), and $42 \%$ of them have a degree and $10 \%$ a master or a PhD. (Table 2 ).

The analysis of other answers about the characterization of SPG consumers gives us the opportunity to provide a more detailed picture of the sample (Table 3). About half of the sample is a veteran with an SPG attendance of 5 years or more 
Table 2 Sample socio-demographic characteristics

\begin{tabular}{|c|c|}
\hline & Percentage \\
\hline \multicolumn{2}{|l|}{ Gender } \\
\hline Male & 34.8 \\
\hline Female & 65.2 \\
\hline Total & 100 \\
\hline \multicolumn{2}{|l|}{ Family size } \\
\hline 1 person & 6.7 \\
\hline 2 persons & 26.3 \\
\hline 3 persons & 25.7 \\
\hline 4 persons & 31.1 \\
\hline 5 or more persons & 10.3 \\
\hline Total & 100 \\
\hline \multicolumn{2}{|l|}{ Income } \\
\hline Low income & 7 \\
\hline Low-middle income & 35.2 \\
\hline Upper-middle income & 38.4 \\
\hline High income & 19.4 \\
\hline Total & 100 \\
\hline \multicolumn{2}{|l|}{ Age } \\
\hline $20-30$ & 2.6 \\
\hline $30-40$ & 21.0 \\
\hline $40-50$ & 30.6 \\
\hline $50-60$ & 29.4 \\
\hline $60-70$ & 14.2 \\
\hline $70-80$ & 2.0 \\
\hline More than 80 & 0.1 \\
\hline Total & 100 \\
\hline \multicolumn{2}{|l|}{ Employment } \\
\hline Employed & 79.4 \\
\hline Not employed & 20.6 \\
\hline Total & 100 \\
\hline \multicolumn{2}{|l|}{ Education } \\
\hline Primary school & 0.1 \\
\hline Lower secondary school & 5.9 \\
\hline Upper secondary school & 41.6 \\
\hline University & 42.3 \\
\hline Master or $\mathrm{PhD}$ & 10.1 \\
\hline Total & 100 \\
\hline
\end{tabular}

Source: our elaborations from sample data

whereas less than $10 \%$ participates for 1 year or less. Most of the members have an active role inside the SPGs and 39\% of them are involved both in the internal organization and in dealing with suppliers. Only $7 \%$ of them use the group occasionally. Regarding the share of food expenditure utilized, there is a consistent part of the sample (40\%) that expends more than $40 \%$ of its food budget in SPGs and 
Table 3 Others features of the sample

\begin{tabular}{|c|c|}
\hline & Percentage \\
\hline \multicolumn{2}{|l|}{ SPG attendance time } \\
\hline 1 year or less & 9.4 \\
\hline 2 years & 13.8 \\
\hline 3 years & 15.3 \\
\hline 4 years & 14.0 \\
\hline 5 years or more & 47.4 \\
\hline Total & 100 \\
\hline \multicolumn{2}{|l|}{ Role inside SPG } \\
\hline I am not actively involved in the organization, and I am an occasional user. & 7 \\
\hline I am not actively involved in the organization, but I am a regular user. & 27.8 \\
\hline I am actively involved in the organization, but I am not dealing with suppliers. & 26 \\
\hline I am actively involved in the organization, and I deal with suppliers. & 39.1 \\
\hline Total & 100 \\
\hline \multicolumn{2}{|l|}{ Percentage of food expenditure from SPG } \\
\hline $0-20 \%$ & 16.1 \\
\hline $20-30 \%$ & 20.1 \\
\hline $30-40 \%$ & 23.1 \\
\hline More than $40 \%$ & 40.6 \\
\hline Total & 100 \\
\hline \multicolumn{2}{|l|}{ Motivation to participate in a SPG } \\
\hline Solidarity with producers and the territory & 24.3 \\
\hline Affordability & 0.5 \\
\hline Quality of food & 41.8 \\
\hline Awareness to environmental issues & 32.5 \\
\hline Opportunity for socialization & 1 \\
\hline Total & 100 \\
\hline \multicolumn{2}{|l|}{ Urban/rural character of SPG participants } \\
\hline Lives in an OECD urban municipality (> 150 people $/ \mathrm{km}^{2}$ ) & 96.9 \\
\hline Lives in an OECD rural municipality $\left(<150\right.$ people $\left./ \mathrm{km}^{2}\right)$ but belonging to a FUA & 1.9 \\
\hline Lives in an OECD rural municipality & 1.2 \\
\hline
\end{tabular}

Source: our elaborations from sample data

only $16 \%$ less than $20 \%$. Interestingly, the main reason to participate in an SPG appears the interest in food quality (41\%) followed by the awareness of the environmental issues. Differently to what happens to other SPGs so far explored (Migliore et al. 2014a), only a quarter of the total states that solidarity with producers and territory is the most important motivation.

Furthermore, we consider the degree of urbanization employing an OECD classification that identifies as urban, those municipalities having a population density greater than 150 people per squared kilometer (OECD 2011). According to this definition, it is remarkable to note that about $97 \%$ of our respondents live in an urban municipality.

\footnotetext{
${ }^{2}$ Functional urban areas (FUA) consist of a densely inhabited city and a less densely populated commuting zone whose labor market is highly integrated with the city (OECD 2012).
} 
Moreover, considering also the functional urban $\operatorname{area}^{2}$ classification, the percentage of urban respondents rises to about $99 \%$. Such evidence is particularly important to our study because it enables us to investigate our research question with a metropolitan focus.

In summary, the consumer type in this sample is a 50-year-old woman, who lives in the city, is in a family with four persons, has a medium to high income and education, attends the SPG for many years, has an active role inside it, and is particularly concerned with the quality of food.

In order to depict an overall picture of SPG participants, we analyzed also ordinal variables of the questionnaire by ordering the score attributed in a descending way (Fig. 2).

The quality and healthiness of food still seem to be the most important motivation to participate in SPG. Participants attribute noticeable importance well above the average score (vertical line in Fig. 2) to seasonal foods followed by awareness about pesticide use in agro-food production and by the importance attributed to fresh products. This set of attributes together with the importance of knowing - and trusting-small producers, and the importance that a food product is GMO-free highlights as SPG consumers are, overall, characterized by a hedonistic profile searching for quality and safety. This characteristic is also confirmed by the other attributes where the score is above the average. Attributes related to the products are preservative-free and organic or information about the production process and nutrition ingredients.

It is remarkable to note that an environmental issue (awareness about water, energy, carbon emission, and $\mathrm{Km} 0$ products) receives fewer interests with respect to healthy characteristics but more than the solidarity with producers and territory.

\section{Factor analysis results}

Prior to performing the analysis, the adequacy of the data matrix was assessed using Bartlett's test of sphericity and the Kaiser-Meyer-Olkin (KMO) measure of sampling

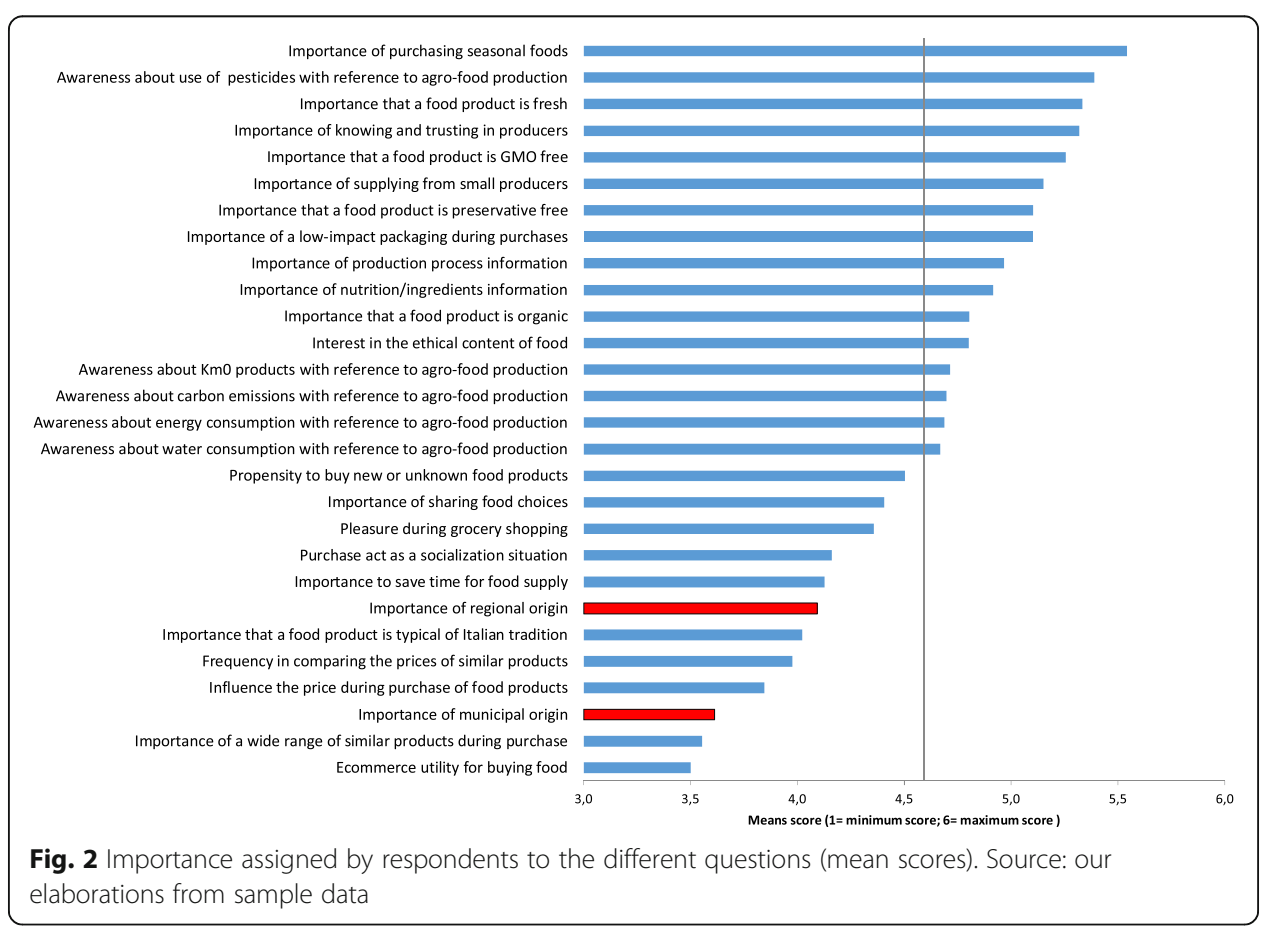


adequacy. We found Bartlett's test significant $\left(\chi^{2}=11,775.5, p<0.00001\right)$, and the KMO measure of the sample adequacy is equal to 0.869 , suggesting that the correlation matrix was suitable for factor analysis. Also, the internal consistency reliability of the variables is high with a Cronbach's alpha of 0.853 .

The rotated component matrix, resulting from an Equamax rotated principal axis factor extraction of the independent variables using the 1.0 eigenvalue cut-off criterion, indicates that 10 factors emerged explaining the $65 \%$ of the total of variance (see Table 4). Results say that the contribution of the first three factors into the overall dispersion accounts for about $30 \%$.

Analyzing the rotated component matrix, we can identify these 10 factors. We named the first one Health factor because it expresses those answers linked to health awareness, like "ingredient information," "preservative-free," "freshness," "GMO-free," and so on. The second factor represents a principally environmental issue and includes awareness about water consumption, carbon emissions, energy consumption, use of pesticides, and $\mathrm{Km} 0$ products. The third one could be thought as responsiveness about Food miles comprising the importance of territorial provenance. The fourth one was labeled Social dimension because it mainly reflects the pleasure during shopping, the importance of sharing food choices, and above all considering purchase act as a socialization situation. The Involvement within SPG (SPG attendance time, role inside SPG and \% food expenditure from SPG) is expressed in factor 5 whereas factor 6 could be thought as SPG values expressing several variables/questions related to the main issues that lie behind SPG ethics: importance of purchasing seasonal foods, importance of supplying from small producers, importance of a low-impact packaging during purchases, importance of knowing and trusting producers, and so on. The seventh factor, named Price, displays a link with all "commercial" issues as the influence of the price during the purchase of food products, the frequency in comparing the prices of similar products, and the importance to have a wide range of similar products during the purchase of food. Factor 8, labeled SocioDemo, represents age and education whereas factor 9, named Time-saving, expresses the variables: importance to save time for food supply and e-commerce utility for buying food. Finally, factor 10 is mainly related to the income variable.

\section{Cluster analysis results}

Afterward, we run the two-step cluster analysis employing these ten factors. This procedure uses a likelihood distance measure which assumes that variables in the cluster model are independent and have a normal (Gaussian) distribution. ${ }^{3}$ To determine which number of clusters is "best," each of these cluster solutions was compared using Schwarz's Bayesian criterion (BIC) as the clustering criterion. At the end of the procedure, the two-step SPSS procedure found four clusters distributed as in Table 5. To assure clusters obtained welldistinguished each other and homogeneous within them, we also perform a one-way analysis of variance (ANOVA) using the ten factors as target variables. Results in Table 6 show that each factor is significant for clusters obtained, so we can conclude that definitions of the segments obtained by clustering is well supported with statistical criterions.

\footnotetext{
${ }^{3}$ In the first step, the procedure begins with the construction of a cluster features (CF) tree by placing the first case at the root of the tree. Each successive case is then added to an existing node or forms a new node, based upon its similarity to existing nodes and using the distance measure as the similarity criterion. In the second step, the leaf nodes of the CF tree are grouped using an agglomerative clustering algorithm.
} 


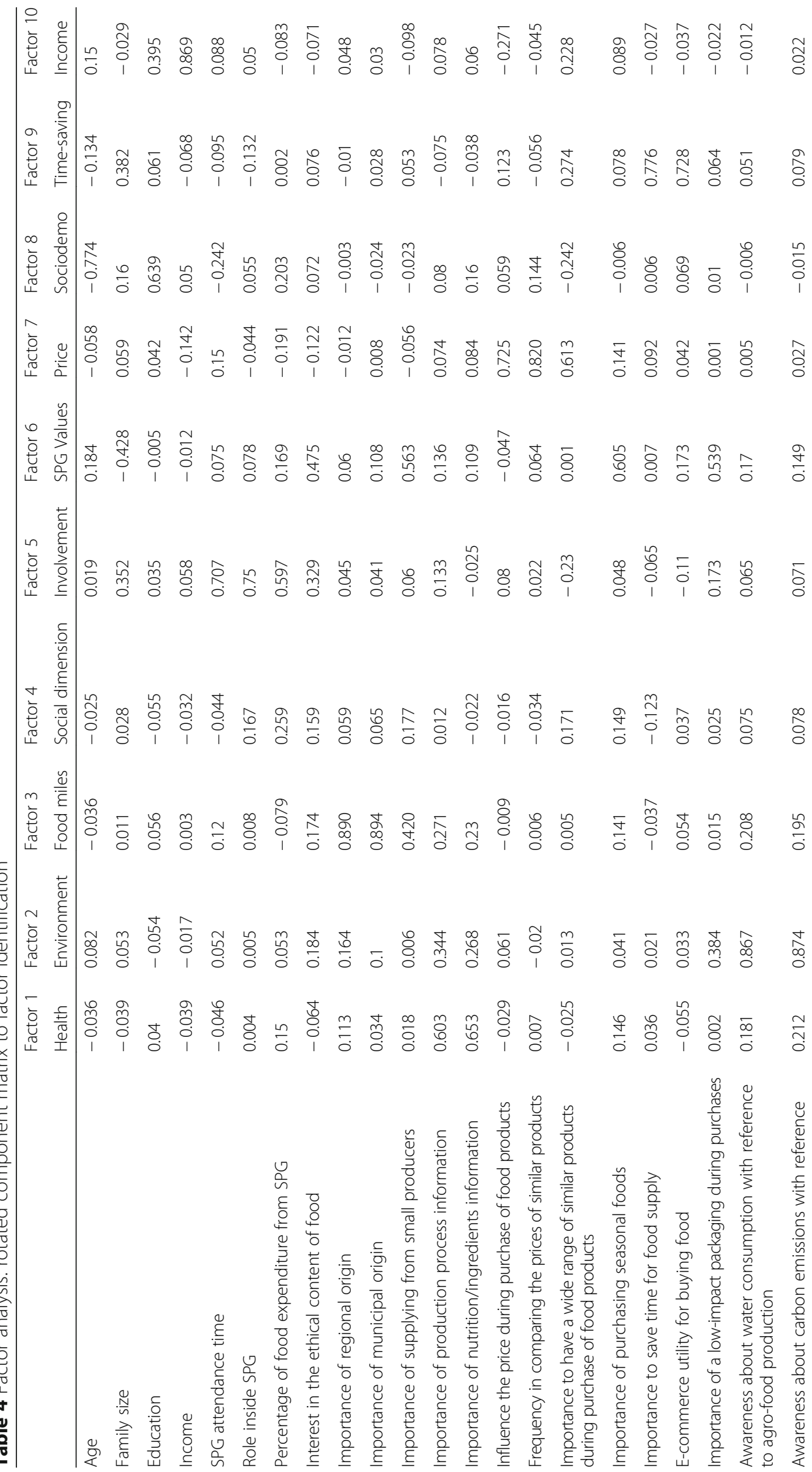




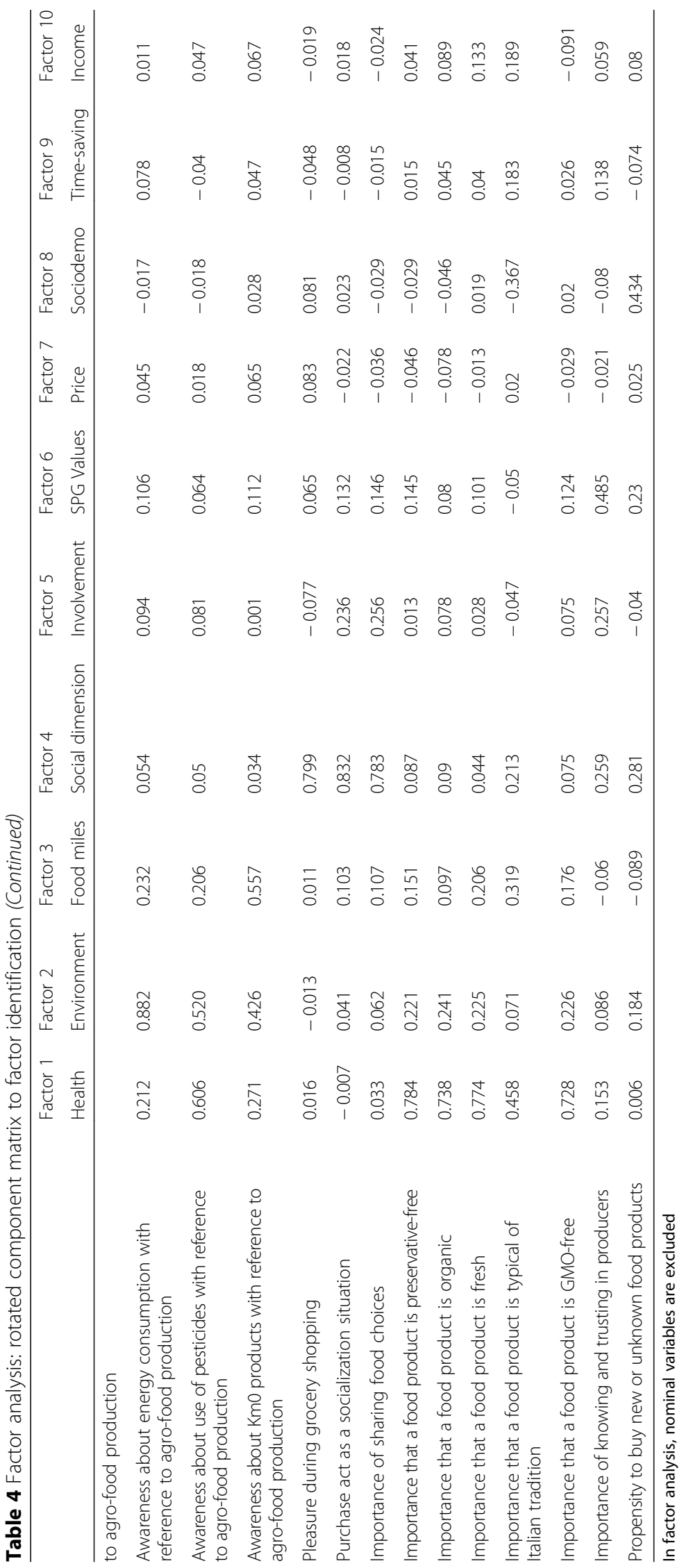


Table $\mathbf{5}$ Cluster sizes

\begin{tabular}{lll}
\hline & Size & Percentage \\
\hline Cluster 1 & 154 & 19.4 \\
Cluster 2 & 369 & 46.4 \\
Cluster 3 & 233 & 29.3 \\
Cluster 4 & 39 & 4.9 \\
Total & 795 & 100.0 \\
\hline
\end{tabular}

From Fig. 3, we can find how well the factors can distinguish different clusters: the higher the importance measure, the less likely the variation for a factor between clusters is due to chance and more likely due to some underlying difference. The health factor appears as the most important, followed by the social factor and the environmental factor. Thus, issues linked to health and food safety (freshness, organic, GMOfree, preservative-free, and so on) represent an essential component, the discriminating factor, which makes the difference between different types of consumers. Time-saving, income, and involvement in the SPG appear a little less significant.

Interpreting the four clusters in light of the respective mean values of the factor scores (Table 6) together with the primary variables provides a lot of information on how the different categories of participants' approach to the SPG experience. Particularly, three reading keys can be used to portray each cluster.

The first one concerns the demographic composition of the groups, which shows a large split between clusters 1 and 2, on one side, and 3 and 4, on the other one. In fact, the first two groups consist-on average-of younger subjects, with a higher educational qualification and a greater share of females.

The second reading key is linked to the role played by participants within the SPGs. In this respect, components of cluster 1 appear to be strongly involved in SPG management, followed by the members of cluster 2, while groups 3 and 4 are configured as representing more passive and occasional users of the SPG.

The third key to better understand clusters' composition is given by the values of the factor scores in the different groups. In general, we can state that clusters 1 and 2 are characterized by positive values of the scores, while the other two groups present generally negative values, albeit with some notable exceptions. This element induces a first

Table 6 Average of factor score for each cluster

\begin{tabular}{llllll}
\hline & Cluster 1 & Cluster 2 & Cluster 3 & Cluster 4 & One-way ANOVA \\
\hline Health (factor 1) & 0.837 & 0.066 & -0.171 & -2.912 & $339.453^{* * *}$ \\
Environment (factor 2) & -0.937 & 0.373 & 0.234 & -1.223 & $126.522^{* * *}$ \\
Food miles (factor 3) & -0.569 & 0.339 & 0.042 & -1.210 & $61.321^{* * *}$ \\
Social dimension (Factor 4) & -0.048 & 0.521 & -0.855 & 0.375 & $140.698^{* * *}$ \\
Involvement (factor 5) & 0.357 & -0.052 & -0.127 & -0.158 & $8.703^{* * *}$ \\
SPG Values (factor 6) & 0.089 & 0.056 & -0.268 & 0.724 & $13.812^{* * *}$ \\
Price (factor 7) & -0.149 & 0.266 & -0.322 & -0.007 & $19.159^{* * *}$ \\
Sociodemographic (factor 8) & 0.454 & 0.124 & -0.449 & -0.288 & $32.769^{* * *}$ \\
Time saving (factor 9) & 0.077 & 0.055 & -0.181 & 0.254 & $4.117^{* * *}$ \\
Income (factor 10) & -0.116 & 0.014 & 0.147 & -0.553 & $6.508^{* * *}$ \\
\hline
\end{tabular}

${ }^{1} \mathrm{~F}$ statistic value

$* * * 1 \%$ level of significance 


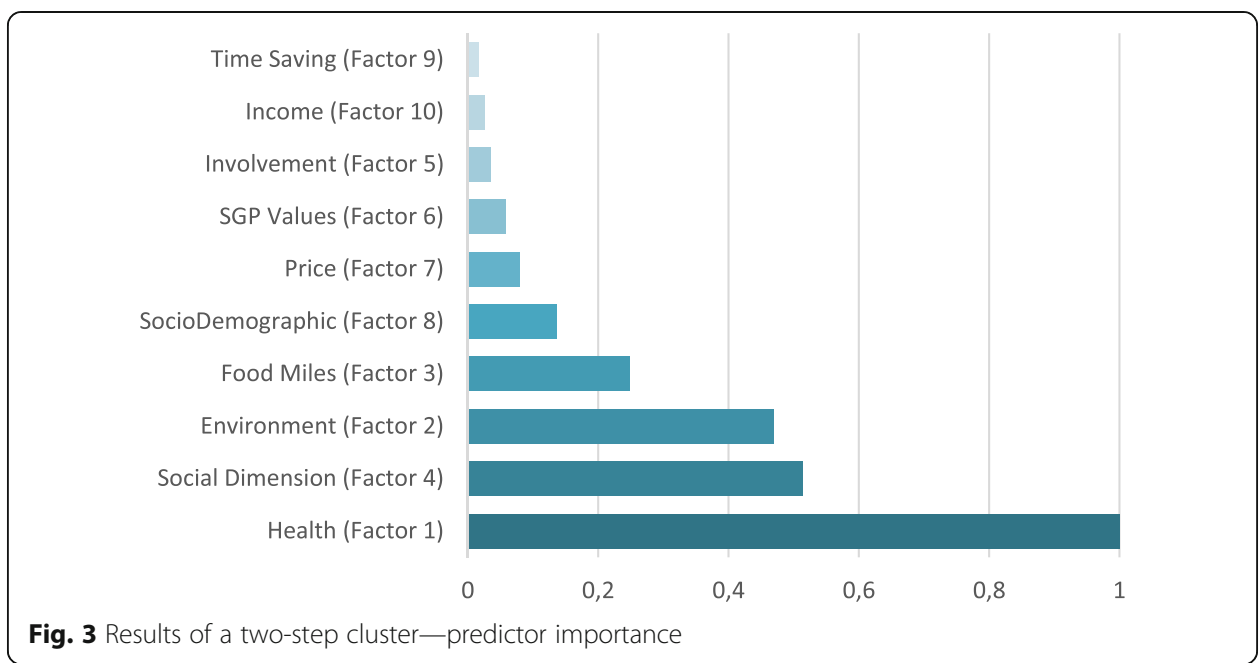

characterization of cluster 4 , and especially cluster 3, mainly in negative terms with respect to clusters 1 and 2. However, this last reading key is also the one that makes it possible to differentiate between groups 1 and 2, and similarly between groups 3 and 4 .

In fact, members of cluster 2 give more attention to aspects related to the environmental sustainability, the territoriality of products, and the social dimension of food consumption.

On the contrary, cluster 1 participants are characterized by a more "hedonistic" approach, with a very high score taken by the factor measuring the importance devoted to health care in guiding food consumption choices, counterbalanced by a relatively limited sensitivity for environmental sustainability and food miles' issues. As regards the last two groups, they are characterized by a generalized skepticism, but members of cluster 4 give importance to the social dimension of being in an SPG and conform more to its values.

In light of these considerations, different approaches to SPGs emerge, revealing some original features compared to the previous evidence of scientific literature, but also some correspondences with a recent article by Zoll et al. (2018).

Accordingly, with previous considerations, we decided to label the four clusters:

- Cluster 1: self-oriented consumers

- Cluster 2: sustainability conscious

- Cluster 3: skeptical satellites

- Cluster 4: socially oriented practitioners

\section{Self-oriented consumers}

This cluster seems to represent a sort of SPG ruling class, highly involved in their management, but guided in its action by individualist drivers, mainly linked to health aspects. From a demographic viewpoint, this group presents the lowest average age (44.7 years toward 49.5 years of the full sample), the highest share of female respondents (72.7\%) and education level. Furthermore, they present the highest incidence of urban residents. Members of cluster 1 are definitely more involved than the others in the SPG activities as they take on more responsibilities in their management (including the choice of suppliers), and a considerable part of their food expenditure is made by an 
SPG. In practice, this group of participants seems to be configured as the steering group that directs choices and takes care of the practical management of the SPGs. However, unexpectedly, they do not pay attention to those attributes that traditional literature ascribes to AFN participants such as environmental concerns, the social dimension of food consumption, and preference for small producers and local food. With particular reference to this last point, the importance of food miles scores only 4.12, while those of regional and periurban origin of food are respectively 3.27 and 2.66 against a more relevant 4.84 scored by the Italian origin attribute. Conversely, parameters linked to food safety, personal health, and own well-being reach very high scores (for instance, absence of preservatives $=5.53, \mathrm{GMO}$-free products $=5.68$, fresh products $=5.72$, and organic food $=5.16$ ). To sum up, they seem convinced that monitoring and tracking their food supply chain and selecting trusted suppliers are solutions to safeguard from industrial foods, perceived as polluted, manipulated, and harmful to health.

\section{Sustainability conscious}

The second cluster, which is the largest, represents active users, with a good degree of involvement, guided by socio-political and environmental motivations, also including food miles and local food issues, but at the same time paying attention to the economic convenience aspects of food consumption. In fact, besides altruistic motivations, they take more into account personal considerations linked to economic convenience and time savings with respect to the other groups. Furthermore, they denote a certain level of involvement in SPG activities (but to a lesser extent with respect to cluster 1). Demographic characteristics of this group indicate that the share of female respondents and the average age in this group are in line with those of the overall sample; $50 \%$ of them are employees. As anticipated, members of this group conform more to the archetype of an SPG participant, for which participation in an AFN represents a way of affirming one's own vision about wide environmental and social questions. Going in depth, they have high scores for the importance of being supplied by small producers (5.36) and sensitivity to water consumption (5.21), GHG emissions (5.21), biodiversity (5.36), food miles (5.20), and animal welfare (5.40). Moreover, cluster 2 presents the highest scores for the importance of the regional and periurban origin of food products (respectively, 4.66 and 4.26), even if the magnitude of these values is not remarkable in absolute. However, as in other clusters, preference for the Italian origin of food (5.35) overcomes that for local products.

\section{Skeptical satellites}

This typology of SPG participants is represented by subjects who are not fundamentally involved in the life of the SPG and who use its services on an occasional basis, without a particular sharing of its values. Cluster 3 selected SPG users with the highest average age (54 years) and a high percentage of males compared to the reference sample. The logical consequence of the demographic profile of this group is the relatively high proportion of retired people. From an economic standpoint, cluster 3 is made up of more affluent subjects. The members of this group are also those who are less involved in the management of SPG, both from the management point of view and from that of the percentage of food expenditure managed through SPG. These two variables clearly define these subjects as relatively passive and occasional users. Furthermore, starting from 
the analysis of the main components, cluster 3 seems to be the most "skeptical" of the four groups with very low values of all factor components, with the exception interest for environmental issues (with regard to the latter factor, it is ranked second after cluster 2). Interestingly, also, variables related to food geographical origin and food miles are placed at an intermediate level between clusters 2 and 1, still underlining that preferences for local food appear less relevant in respect to other food products. On the opposite, the "social dimension" component, linked to the perception of food spending as a moment of pleasure, socialization, and sharing, is lowly considered. Also, the component related to the adhesion to the gas values places this group in the last place in relation to the value of the corresponding factor.

\section{Socially oriented practitioners}

Finally, this group is configured as a small niche and in some ways separated from the socio-demographic point of view, whose components, although are not very involved in the management of the SPGs, appreciate its social meaning and share its values. Cluster 4 is rather residual from the numerical point of view as it includes only 39 subjects (4.9\% of the total). The socio-demographic profile aligns enough of this cluster, characterized by relatively elder members and with the highest incidence of male respondents with cluster 3. However, there is a strong difference linked to income, which is clearly lower here. The subjects belonging to cluster 4 are also relatively involved little in the management of the SPGs; however, they are also those who show greater conformity to its values (SPG value factor $=0.724$ ) and fair importance attributed to the social dimension. On the contrary, the health and environmental components and all the basic variables that compose them present very low values. This modest perception of these issues could find a partial explanation also in the low education level of the members.

\section{Discussion and conclusion}

This paper aimed to assess how Solidarity Purchase Groups (SPGs) work in a metropolitan area of Italy. To this end, we developed the study in some provinces of Lombardy region, in Northern Italy, characterized by a very high degree of urbanization and economic development.

As in this area is concentrated about one half of the SPGs located on the Lombardy region, it appears very interesting to understand if specific characteristics of this context affect the motivations of SPGs members, providing a characterization of them.

We carried out a web survey on 795 consumers involved in 125 SPGs that represent about $12.5 \%$ of the total of SPGs in Italy. The questionnaire is divided into 7 sections and contains 39 questions of which 35 have a Likert scale. By factor analysis, we found 10 factors explaining $65 \%$ of the total variance. We used these factors as variables to identify 4 clusters, obtained using the two-step cluster procedure.

According to some literature (Cone and Myhre 2000; Brehm and Eisenhauer 2008; Dobernig and Stagl 2015; Krikser et al. 2016), our descriptive results provide relevant information showing that the main reason to participate in SPGs is the interest in food quality, followed by environmental issues, whereas solidarity toward small producers is only in the third position. Among the different food attributes searched by consumers through the SPG channel is relevant to highlight what they experience about the origin 
of products. In contrast to literature (Lombardi et al. 2015; Migliore et al. 2014a; Gilg and Battershill 1998), SPG members interviewed in this study seem more prone to searching for non-local products. The importance of periurban and regional origin show very low interest in respect to other attributes, and this aversion is probably related to the specific characteristic of the study area, heavily urbanized and with a high density of industrial activity. Even if there are a lot of high-quality regional products, the perception of a territory characterized by a commingling of intensive agriculture and productive activities discourages consumers from local products, putting attention back to products coming from other Italian regions.

This general tendency found confirmation in the cluster analysis, aimed at identifying homogeneous groups of SPG participants. Indeed, members belonging to the group that is more involved in SPG management (cluster 1) appear less interested in local food, giving priority to food healthiness and safety attributes. These results highlight as metropolitan SPG consumers seem to be untied by "local food trap" prejudice (Born and Purcell 2006), stating that local food is inherently good.

It is worthy of interest that SPGs in a metropolitan area, such as that of Milan, in a certain sense conform to some tendencies of massive food consumption that apparently they should criticize.

First of all, the system of values animating their consumers does not fully conform to that traditionally attributed to an AFN. In fact, hedonistic components coexist, and in certain sense prevail, on ethical considerations. This is in line with the study of Zoll et al. (2018), who demonstrate that eating healthy food is the most important factor of the participation to AFNs, whereas social or environmental reasons are less pronounced. Furthermore, among altruistic motives, those linked to environmental issues overcome considerations associated with socialization and solidarity toward small producers. In fact, similarly with other types of AFNs and other Italian SPGs (Hashem et al. 2018; Lombardi et al. 2015; Sage 2014; Tregear 2011, Winter 2003), the awareness toward environmental issues is an important factor affecting participation to SPGs.

Second, local and typical products are not perceived as an important driver of food consumption, and as a consequence metropolitan SPGs do not consider particularly desirable regional and periurban food productions. Observing the SPGs from this perspective, contrary to what was claimed by Feenstra (1997), it emerges as AFNs can flourish also in those places where the lack of connection with the territory is counterbalanced by the high motivation to buy products from trusted suppliers not necessarily located nearby.

Finally, the organization of metropolitan SPGs takes on a high degree of complexity that somehow reflects that of large-scale food distribution. Given the large number of SPGs and their participants, the responsibility of choosing and keeping in touch with suppliers is in the hands of a restricted range of practitioners or, in some cases, is delegated to higher-level SPGs (or nets of SPGs) that manage supplies and redistribute them to smaller groups. It is indicative from cluster results that members who are more involved in SPG management are the ones most marked by individualistic motives and by a lack of interest in local food productions.

Such a picture would seem to lead metropolitan SPGs and local farmers on two separate paths. The first one is dedicated to rationalize their organization and to expand the range of their suppliers toward selected subjects, also able to guarantee important 
volumes. The second is partly dedicated to direct selling on the farm as a form of business diversification.

Having taken note of SPG participants' motives, pointing our attention to the periurban farmer's side, one wonders if a direct selling approach has further development margins, such as to represent a reasonable perspective also for the mass of industrial farmers, whose production model seems to be increasingly in crisis. In this sense, SPGs could potentially represent a proficient solution to diversify farm businesses. We think that farmer's markets do not have ample room for further development as they are not able to reach a wide audience, in addition to presenting several other limits well evidenced in the paper of Jarosz (2008). In this sense, SPGs could potentially represent a valid alternative to diversify periurban farm businesses, but developing this opportunity would require a deep rethinking of the organization of metropolitan producers. To relate with SPGs, they should cooperate in order to offer large volumes and a wide range of products, but overall, they should be more conformed to satisfy the needs of SPG participants, as they are emerged by our study. Particularly, food safety and healthiness represent an element of criticism for farmers operating in a territorial context compromised from the environmental viewpoint as the metropolitan area of Milan.

This paper has some limitations since the study was carried out only in a welldefined area characterized by a high level of urbanization but does not compare the results with SPGs located in less urbanized or rural areas. Future works should utilize the same survey on SPGs located in other regions to highlight the possible differences. Its implications are, however, important to stimulate some critical thinking about the development of these different forms of alternative food networks (AFNs).

\section{Acknowledgements}

Not applicable.

Authors' contributions

LB has written the "The questionnaire" section and the "Factor analysis results" section. DB has written the "The reference area" section and the "Cluster analysis results" section. GM has written the "Introduction" section. MP has written the "The empirical approach" section and the "Descriptive results" section. The "Discussion and conclusion" section has been jointly written by all the authors. All the authors read and approved the final manuscript.

Funding

Not applicable.

\section{Availability of data and materials}

The datasets generated and/or analyzed during the current study are not publicly available due to privacy reasons, but are available from the corresponding author on reasonable request.

Competing interests

The authors declare that they have no competing interests.

\section{Author details}

${ }^{1}$ Department of Environmental Science and Policy, Università degli Studi di Milano, Via Celoria 2, Milan, Italy.

${ }^{2}$ Department of Agricultural, Food and Forest Sciences (SAAF), University of Palermo, Viale delle Scienze 13, Palermo, Italy.

Received: 11 January 2019 Accepted: 23 September 2019

Published online: 04 November 2019

References

Angelici, L., Piola, M., Cavalleri, T., Randi, G., Cortini, F., Bergamaschi, R., Baccarelli, A.A., Bertazzi, P.A., Pesatori, A.C., \& Bollati, V. (2016). Effects of particulate matter exposure on multiple sclerosis hospital admission in Lombardy region, Italy. Environ Res, 145, 68-73. https://doi.org/10.1016/j.envres.2015.11.017

Banfield JD, Raftery AE (1993) Model-based Gaussian and non-Gaussian clustering. Biometrics, 49:803-821. https://doi.org/10 $2307 / 2532201$ 
Blasi, E., Cicatiello, C., Pancino, B., \& Franco, S. (2015). Alternative food chains as a way to embed mountain agriculture in the urban market: the case of Trentino. Agricultural and Food Economics, 3(1), 1-13. https://doi.org/10.1186/s40100-014-0023-0

Born, B., \& Purcell, M. (2006). Avoiding the local trap: scale and food systems in planning research. J Plan Educ Res, 26(2), 195-207. 10.1177\%2F0739456X06291389

Brehm, J.M., \& Eisenhauer, B.W. (2008). Motivations for participating in community-supported agriculture and their relationship with community attachment and social capital. South Rural Sociol, 23(1), 94-115

Brunori, G., Rossi, A., \& Guidi, F. (2012). On the new social relations around and beyond food. Analysing consumers' role and action in Gruppi di Acquisto Solidale (Solidarity Purchasing Groups). Sociol Rural, 52(1), 1-30. https://doi.org/10.1111/j. 1467-9523.2011.00552.x

Brunsø, K., \& Grunert, K.G. (1995). Development and testing of a crossculturally valid instrument: food-related life-style. Advances in Consumer Research, volume 22, eds. Frank R. Kardes and Mita Sujan, Provo, UT: Association for Consumer Research, 475-480

Caiani, G., Guastella, G., Pareglio, S., Pozzi, F., \& Solero, E. (2015). Periurban agriculture in Lombardy between urban sprawl, multifunctionality and new lifestyles: towards a territorial approach for rural development. Aestimum, 89-100. https://doi. org/10.13128/Aestimum-17886

Canedoli, C., Crocco, F., Comolli, R., \& Padoa-Schioppa, E. (2018). Landscape fragmentation and urban sprawl in the urban region of Milan. Landsc Res, 43(5), 632-651. https://doi.org/10.1080/01426397.2017.1336206

Carbone, A. (2017). Food supply chains: coordination governance and other shaping forces. Agricultural and Food Economics, 5(1), 3. https://doi.org/10.1186/s40100-017-0071-3

Cembalo, L., Migliore, G., \& Schifani, G. (2012). Consumers in postmodern society and alternative food networks: the organic food fairs case in Sicily. New Medit, 11(3), 41-49

Cembalo, L., Migliore, G., \& Schifani, G. (2013). Sustainability and new models of consumption: the Solidarity Purchasing Groups in Sicily. J Agric Environ Ethics, 26(1), 281-303. https://doi.org/10.1007/s10806-011-9360-0

Cone, C., \& Myhre, A. (2000). Community-supported agriculture: a sustainable alternative to industrial agriculture? Hum Organ, 59, 187-197. https://www.jstor.org/stable/44126935

Contini, C., Romano, C., Boncinelli, F., Scozzafava, G., \& Casini, L. (2017). Does 'local' matter in restaurant choice? Results of a discrete choice experiment targeting German and Italian consumers. Agricultural and Food Economics, 5(1), 21. https:// doi.org/10.1186/s40100-017-0092-y

De Meij, A., Thunis, P., Bessagnet, B., \& Cuvelier, C. (2009). The sensitivity of the CHIMERE model to emissions reduction scenarios on air quality in northern Italy. Atmos Environ, 43(11), 1897-1907. https://doi.org/10.1016/j.atmosenv.2008.12.036

Del Giudice, T., Cavallo, C., Caracciolo, F., \& Cicia, G. (2015). What attributes of extra virgin olive oil are really important for consumers: a meta-analysis of consumers' stated preferences. Agricultural and Food Economics, 3(1), 20. https://doi.org/ 10.1186/s40100-015-0034-5

Dobernig, K., \& Stagl, S. (2015). Growing a lifestyle movement? Exploring identity-work and lifestyle politics in urban food cultivation: growing a lifestyle movement? Int J Consum Stud, 39, 452-458. https://doi.org/10.1111/ijcs.12222

EEA (2015). Air quality in Europe - 2015 Report, EEA Report. No. 5/2015, Copenhagen, 57 pp. ISBN 978-92-9213-702-10.2800/ 62459

Esposito S, Galeone C, Lelii M, Longhi B, Ascolese B, Senatore L, Prada L, Montinari V, Malerba S, Patria MA, Principi N (2014) Impact of air pollution on respiratory diseases in children with recurrent wheezing or asthma. BMC pulmonary medicine 14(1):130. https://doi.org/10.1186/1471-2466-14-130

Feenstra GW (1997) Local food systems and sustainable communities. Am J Altern Agric 12(1):28-36. https://doi.org/10.1017/ S0889189300007165

Fonte M (2013) Food consumption as social practice: Solidarity Purchasing Groups in Rome, Italy. J Rural Stud 32:230-239. https://doi.org/10.1016/j.jurstud.2013.07.003

Galli F, Bartolini F, Brunori G, Colombo L, Gava O, Grando S, Marescotti A (2015) Sustainability assessment of food supply chains: an application to local and global bread in Italy. Agricultural and Food Economics 3(1):21. https://doi.org/10.1186/ s40100-015-0039-0

Giampietri E., Finco A. and Del Giudice T. (2016). Exploring consumers' behaviour towards short food supply chains, Br Food J, 118(3), 618-631. https://doi.org/10.1108/BFJ-04-2015-0168

Gilg AW, Battershill M (1998) Quality farm food in Europe: a possible alternative to the industrialised food market and to current agri-environmental policies: lessons from France. Food Policy 23(1):25-40. https://doi.org/10.1016/50306-9192(98)00020-7

Grasseni, C. (2013). Beyond alternative food networks: Italy's solidarity purchase groups. A\&C Black

Graziano PR, Forno F (2012) Political consumerism and new forms of political participation: the Gruppi di Acquisto Solidale in Italy. The ANNALS of the American Academy of Political and Social Science 644(1):121-133 10.1177\%2F0002 716212454839

Hashem S, Migliore G, Schifani G, Schimmenti E, Padel S (2018) Motives for buying local, organic food through English box schemes. Br Food J 120(7):1600-1614. https://doi.org/10.1108/BFJ-08-2017-0426

Hemmerling, S., Hamm, U., \& Spiller, A. (2015). Consumption behaviour regarding organic food from a marketing perspective - a literature review. Org Agric, 5 (4), 277-313. https://doi.org/10.1007/s13165-015-0109-3

ISTAT (2011). Censimento Agricoltura 2010. Istituto Nazionale di Statistica, Roma, Italia. http://dati-censimentoagricoltura.istat. it/lndex.aspx?lang=it

Istat (2018). Rapporto annuale 2018 - La situazione del Paese, Istituto Nazionale di Statistica, Roma, Italia. https://www.istatit/ it/archivio/214230

Jarosz L (2008) The city in the country: growing alternative food networks in metropolitan areas. J Rural Stud 24(3):231-244. https://doi.org/10.1016/j.jurstud.2007.10.002

Krikser T, Piorr A, Berges R, Opitz I (2016) Urban agriculture oriented towards self-supply, social and commercial purpose: a typology. Land 5:28. https://doi.org/10.3390/land5030028

Kuznesof S, Tregear A, Moxey A (1997) Regional foods: a consumer perspective. British Food Journal, 99(6):199-206. https:// doi.org/10.1108/00070709710181531

Lenhart A, Horrigan J, Rainie L, Allen K, Boyce A, Madden M (2003) The ever-shifting internet population: a new look at internet access and the digital divide. Pew Internet \& American Life Project, Washington, DC 
Lombardi, A., Migliore, G., Verneau, F., Schifani, G., \& Cembalo, L. (2015). Are "good guys" more likely to participate in local agriculture? Food Qual Prefer, 45, 158-165. https://doi.org/10.1016/j.foodqual.2015.06.005

Lombardi GV, Berni R, Rocchi B (2017) Environmental friendly food. Choice experiment to assess consumer's attitude toward "climate neutral" milk: the role of communication. J Clean Prod 142:257-262. https://doi.org/10.1016/j.jclepro.2016.05.125

Martino G, Giacchè G, Rossetti E (2016) Organizing the co-production of health and environmental values in food production: the constitutional processes in the relationships between Italian Solidarity Purchasing Groups and farmers. Sustainability 8:316. https://doi.org/10.3390/su8040316

Micheels ET, Boecker A (2017) Competitive strategies among Ontario farms marketing direct to consumers. Agricultural and Food Economics 5(1):10. https://doi.org/10.1186/s40100-017-0079-8

Migliore, G., Caracciolo, F., Lombardi, A., Schifani, G., \& Cembalo, L. (2014b). Farmers' participation in civic agriculture: the effect of social embeddedness. Culture, Agriculture, Food and Environment, 36(2), 105-117. https://doi.org/10.3390/su8040316

Migliore G, Schifani G, Guccione GD, Cembalo L (2014a) Food community networks as leverage for social embeddedness. J Agric Environ Ethics 27(4):549-567. https://doi.org/10.1007/s10806-013-9476-5

Migliore G, Schifani G, Romeo P, Hashem S, Cembalo L (2015) Are farmers in alternative food networks social entrepreneurs? Evidence from a behavioral approach. J Agric Environ Ethics 28(5):885-902. https://doi.org/10.1007/s10806-015-9562-y

Norris, P. (Ed.). (1999) Critical citizens: Global support for democratic government. OUP Oxford

OECD (2011) "OECD regional typology" (methodology document), Directorate for Public Governance and Territorial. Development, Paris http://www.oecd.org/gov/regionalpolicy/OECD_regional_typology_Nov2012.pdf

OECD (2012). Redefining urban: a new way to measure metropolitan areas. Organisation for economic cooperation and development (OECD), publishing, \& organisation for economic co-operation and development staff, 2012

Paracchini ML, Bulgheroni C, Borreani G, Tabacco E, Banterle A, Bertoni D, Rossi G, Parolo G, Origgi R, De Paola C (2015) A diagnostic system to assess sustainability at a farm level: the SOSTARE model. Agric Syst 133:35-53. https://doi.org/10. 1016/j.agsy.2014.10.004

Pieri, R., \& Pretolani, R. (Eds.). (2017). II sistema agro-alimentare della Lombardia: Rapporto 2016. FrancoAngeli. ISBN 978-88917-5114-0

Sacchi, G. (2018). The ethics and politics of food purchasing choices in Italian consumers' collective action. J Agric Environ Ethics, 31(1):73-91. https://doi.org/10.1007/s10806-018-9710-2

Sage C (2014) The transition movement and food sovereignty: from local resilience to global engagement in food system transformation. J Consum Cult 14(2):254-275 10.1177\%2F1469540514526281

Shannon CE (1948) A mathematical theory of communication. Bell System Technical Journal 27(379-423):623-656

SPSS (2001) The SPSS two-step cluster component: a scalable component to segment your customers more effectively. White paper-technical report, Chicago 2001:1-9

Tempesta T, Vecchiato D (2013) Riverscape and groundwater preservation: a choice experiment. Environ Manag 52(6):14871502. https://doi.org/10.1007/s00267-013-0163-0

Travisi CM, Nijkamp P (2008) Valuing environmental and health risk in agriculture: a choice experiment approach to pesticides in Italy. Ecol Econ 67(4):598-607. https://doi.org/10.1016/j.ecolecon.2008.01.011

Tregear A (2011) Progressing knowledge in alternative and local food networks: critical reflections and a research agenda. J Rural Stud 27(4):419-430. https://doi.org/10.1016/j.jrurstud.2011.06.003

Winter N (2003) Social capital, civic engagement, and positive youth development outcomes. Policy Studies Associates, Inc., Washington, DC

Wright KB (2006) Researching internet-based populations: advantages and disadvantages of online survey research, online questionnaire authoring software packages, and web survey services. J Comput-Mediat Commun 10:3. https://doi.org/10. 1111/j.1083-6101.2005.tb00259.x

Xu P, Wang Z (2014) Country of origin and willingness to pay for pistachios: a chinese case. Agricultural and Food Economics 2(1):14. https://doi.org/10.1186/s40100-014-0014-1

Zepeda L, \& Leviten-Reid C (2004) Consumers' views on local food. Journal of food distribution Research, 35(856-201656647): $1-6$

Zhang, T., Ramakrishnon, R., \& Livny, M. (1996). BIRCH: an efficient data clustering method for very large databases. Proceedings of the ACM SIGMOD Conference on Management of Data.P. 103-114, Montreal, Canada

Zoll F, Specht K, Opitz I, Siebert R, Piorr A, Zasada I (2018) Individual choice or collective action? Exploring consumer motives for participating in alternative food networks. Int J Consum Stud 42(1):101-110. https://doi.org/10.1111/ijcs.12405

\section{Publisher's Note}

Springer Nature remains neutral with regard to jurisdictional claims in published maps and institutional affiliations. 